\title{
miR-494-BAG-1 axis is involved in cinobufacini-induced cell proliferation and apoptosis in gastric cancer
}

\author{
ZHILI SHEN $^{1^{*}}$, YAN LI $^{2 *}$, CHENGCHENG ZHAO $^{3}$, FEN WANG $^{1}$, RONGPING ZHOU ${ }^{1}$ and GANG CHEN ${ }^{1}$ \\ ${ }^{1}$ Department of Oncology; ${ }^{2}$ Clinical Laboratory; ${ }^{3}$ Central Laboratory, \\ The Affiliated Jiangning Hospital of Nanjing Medical University, Nanjing, Jiangsu 210000, P.R. China
}

Received October 1, 2016; Accepted February 2, 2018

DOI: $10.3892 / \mathrm{mmr} .2018 .8788$

\begin{abstract}
Cinobufacini is widely used in the treatment of advanced cancers. It has been previously reported that microRNA (miR)-494 was upregulated in cinobufacini-treated gastric cancer cells; however, the detailed role of miR-494 in the anti-tumor activity of cinobufacini is unclear. The present study aimed to clarify the function of miR-494 in cinobufacini-induced cell behavior changes. Cell viability and proliferation ability were investigated using a Cell Counting Kit-8 assay. Flow cytometry was performed to investigate the apoptosis rate of gastric cancer (GC) cells. The mRNA expression levels of microRNA (miR)-494 and BCL2 associated athanogene 1 (BAG-1) were investigated using reverse transcription-quantitative polymerase chain reaction, and the protein expression level of BAG-1 was investigated using western blot assays. The results demonstrated that treatment with cinobufacini suppressed proliferation and promoted apoptosis of gastric cancer cells. miR-494 acts as a tumor suppressor gene in gastric cancer. In cinobufacini-treated cells, miR-494 and BAG-1 exhibited opposing expression trends. Furthermore, knockdown of miR-494 in cinobufacini-treated cells upregulated the protein expression level of BAG-1, promoted cell proliferation and inhibited cell apoptosis. In addition, inhibition of BAG-1 using small interfering RNA in cinobufacini-treated cells partially abrogated the effects of miR-494 inhibitor on cell proliferation and apoptosis. Thus, these results suggest that cinobufacini suppresses GC cells proliferation and promotes apoptosis partially through
\end{abstract}

Correspondence to: Dr Rongping Zhou or Dr Gang Chen, Department of Oncology, The Affiliated Jiangning Hospital of Nanjing Medical University, 168 Gushan Road, Nanjing, Jiangsu 210000, P.R. China

E-mail: pinger_523@126.com

E-mail: otga@sina.com

${ }^{*}$ Contributed equally

Key words: microRNA-494, BCL2 associated athanogene 1, cinobufacini, gastric cancer the regulation of miR-494-BAG-1 axis, which may provide a novel insight into the functional mechanism of cinobufacini.

\section{Introduction}

Gastric cancer (GC) is a common digestive system tumor worldwide, with high incidence and mortality rates, particularly in eastern Asia (1). In China, GC ranks as the second most prevalent malignancy, with 679,100 new cases and 498,000 mortalities in 2015 (2). Chemotherapy is an efficient treatment for patients with GC, however, the majority of chemotherapeutic agents cause significant side effects in patients. Thus, development of more effective therapies for the treatment of GC is required.

Cinobufacini, which is extracted from the skin and parotid venom glands of the toad Bufo gargarizans, is extensively used in the treatment of patients with advanced cancer in China $(3,4)$. Several studies have demonstrated the anti-neoplastic activities of cinobufacini, including inhibiting cancer cell proliferation (4), inducting cell apoptosis (5), causing cell cycle arrest and cytoskeleton function (6), exerting genotoxic effects (7) and others. A meta-analysis of GC treatments concluded that cinobufacini combined with chemotherapy provide benefits for advanced GC (8). Yang et al (9) reported that cinobufacini improved leukopenia and exhibited benefit for adverse events in the digestive system caused by chemotherapy. However, the detailed molecular mechanism of action of cinobufacini in the treatment of GC is not fully elucidated.

MicroRNAs (miRNAs/miRs) are a class of post-transcriptional regulators that participate in the regulation of a wide variety of cellular functions (10). Dysregulated miRNAs expression patterns have been commonly found in various cancer types $(11,12)$. miR-494 is located at chromosome $14 \mathrm{q} 32.31$ (13). It has been reported that miR-494 can act as an oncogene or tumor suppressor gene in different cancer types, and influences various stages of tumorigenesis $(11,14,15)$. Our previous study revealed that miR-494 was upregulated in cinobufacini-treated GC cells (16). Accordingly, whether the anti-tumor effects of cinobufacini are mediated by miR-494 as examined in the current study.

In the present study it is reported that cinobufacini inhibited proliferation and promoted apoptosis of GC cells. Additionally, miR-494 was downregulated in the plasma of patients with GC, and knockdown of miR-494 in cinobufacini-treated cells promoted cell proliferation and inhibited apoptosis. 
Furthermore, the effects of miR-494 on cinobufacini-induced cell proliferation and apoptosis were mediated by BCL2 associated athanogene 1 (BAG-1).

\section{Materials and methods}

Blood samples and plasma preparation. This study was approved by the Ethical Committee of Nanjing Jiangning Hospital (Nanjing, China). Written informed consent was obtained from all of the participants. Blood samples from 50 cases of patients with GC (31 males and 19 females; aged 51-81 years old) and 50 healthy control subjects ( 30 males and 20 females; aged 54-82 years old) were collected in Nanjing Jiangning Hospital during December 2015 and October 2016. Blood samples of patients with GC were collected who were first diagnosed with cancer via histopathological examination, and negative control blood samples were obtained from healthy control subjects (all of whom did not suffer from cancer) visited the same hospital for physical examinations in the same period. Blood samples were centrifuged at $1,800 \mathrm{xg}$ for $5 \mathrm{~min}$ to separate the plasma. All the plasma samples were stored at $-80^{\circ} \mathrm{C}$ prior to RNA extraction.

Cell lines. The human GC cell lines (BGC-823 and SGC-7901) were purchased from the Cell Bank of the Chinese Academy of Sciences (Shanghai, China). Cells were cultured in RPMI-1640 medium (Invitrogen; Thermo Fisher Scientific, Inc., Waltham, MA, USA) supplemented with 10\% FBS (Invitrogen; Thermo Fisher Scientific, Inc.), $100 \mathrm{U} / \mathrm{ml}$ penicillin and streptomycin (Invitrogen; Thermo Fisher Scientific, Inc.), and incubated at $37^{\circ} \mathrm{C}$ with $5 \% \mathrm{CO}_{2}$.

Cell transfection. Cells $\left(3 \times 10^{5}\right)$ were seeded into 6-well plates and transiently transfected with $50 \mathrm{nM}$ miRNA inhibitor, miRNA negative control (NC) or $50 \mathrm{nM}$ small interfering RNA (siRNA) using Lipofectamine ${ }^{\circledR} 2000$ (Invitrogen; Thermo Fisher Scientific, Inc.) when the cell confluence reached 70-90\%. The miR-494 inhibitor and negative control were purchased from Guangzhou RiboBio Co., Ltd. [Guangzhou, China; cat. nos. miR20002816-1 and miR02201-1-5 (sequences not available)] and the BAG-1 siRNA was synthesized by Genepharma (Shanghai, China). The BAG-1 siRNA sequence was 5'-GGG AAAAUCUCUGAAGGAAtt-3' (17). The medium was replaced with fresh medium $6 \mathrm{~h}$ post-transfection. The expression level of miR-494 or BAG-1 was measured after 48 or $72 \mathrm{~h}$, respectively.

Cell proliferation assay. Cells were seeded, at a density of


time-points $(24,48$ and $72 \mathrm{~h})$, the optical density value was measured by Cell Counting Kit-8 (CCK-8; Dojindo Molecular Technologies, Inc., Kumamoto, Japan) on an iMark microplate reader (Bio-Rad Laboratories, Inc., Hercules, CA, USA) at $450 \mathrm{~nm}$ after $2 \mathrm{~h}$ incubation with the CCK-8 reagent.

Flow cytometry. Cell apoptosis was analyzed with an Annexin V-propidium iodide apoptosis detection kit (Nanjing KeyGen Biotech Co., Ltd., Nanjing, China) on a flow cytometer (BD Biosciences, Franklin Lakes, NJ, USA). Briefly, A total of $48 \mathrm{~h}$ post-transfection, $5 \times 10^{5}$ cells were harvested and washed twice in cold PBS, and suspended in binding buffer. Following incubation with Annexin V-fluorescein isothiocyanate and propidium iodide for $10 \mathrm{~min}$ in the dark, at room temperature, cells were subjected to flow cytometry assay analysis.

Reverse transcription-quantitative polymerase chain reaction $(R T-q P C R)$. A total of $48 \mathrm{~h}$ post-transfection, total RNA from $1 \times 10^{6}$ cells was isolated using TRIzol reagent (Thermo Fisher Scientific, Inc.) and RT was performed using PrimeScript ${ }^{\mathrm{TM}}$ RT reagent kit with gDNA Eraser (Takara Bio, Inc., Otsu, Japan) following to the manufacturer's instructions. The incubation conditions of RT were $42^{\circ} \mathrm{C}$ for $2 \mathrm{~min}, 37^{\circ} \mathrm{C}$ for $15 \mathrm{~min}$ and $85^{\circ} \mathrm{C}$ for $5 \mathrm{sec}$. The qPCR reaction was performed on an ABI StepOne Plus System (Thermo Fisher Scientific, Inc.), and the cycling conditions were $95^{\circ} \mathrm{C}$ for $30 \mathrm{sec}$, followed by 40 cycles of $95^{\circ} \mathrm{C}$ for $5 \mathrm{sec}$ and $60^{\circ} \mathrm{C}$ for $30 \mathrm{sec}$. The $\beta$-actin or U6 were used as the internal control. The primer sequences were as follows: miR-494, forward 5'-TGACCTGAAACATAC ACGGGA-3' and reverse 5'-TATCGTTGTACTCCACTCCTT GAC-3'; U6, forward 5'-ATTGGAACGATACAGAGAAGA TT-3' and reverse 5'-GGAACGCTTCACGAATTTG-3'; The expression of the target genes were calculated using the $2^{-\Delta \Delta C q}$ method (18).

Western blot analysis. A total of $72 \mathrm{~h}$ post-transfection, $1 \times 10^{6}$ cells were trypsinized and lysed in radioimmunoprecipitation assay lysis buffer (Beyotime Institute of Biotechnology, Haimen, China) for $10 \mathrm{~min}$ on ice. Proteins were isolated by centrifuging at $12,000 \mathrm{xg}$ for $5 \mathrm{~min}$ at $4^{\circ} \mathrm{C}$. The protein concentration was determined by the bicinchoninic acid (BCA) method using the BCA Protein Assay kit (Beyotime Institute of Biotechnology). Equal amounts of proteins $(30 \mu \mathrm{g})$ were separated on 10\% SDS-PAGE and transferred to polyvinylidene difluoride membranes, and then incubated in blocking buffer (5\% non-fat milk in tris-buffered saline with $0.05 \%$ Tween-20) at room temperature for $1 \mathrm{~h}$. The membranes were incubated with the primary antibodies of $\beta$-actin (cat. no. A5441; mouse monoclonal; 1:8,000; Sigma-Aldrich; Merck KGaA, Darmstadt, Germany) and BAG-1 (cat. no. ab32109; rabbit monoclonal; 1:500; Abcam, Cambridge, UK) overnight at $4^{\circ} \mathrm{C}$. Following washing in TBS-Tween, the membrane was incubated in secondary antibodies (cat. no. ZB-2301, goat anti-rabbit; cat. no. ZB-2305, goat anti-mouse; 1:10,000; OriGene Technologies, Inc., Beijing, China) for $2 \mathrm{~h}$. Protein bands were detected using an enhanced chemiluminescence kit (Pierce; Thermo Fisher Scientific, Inc.) on a FluorChem E System (ProteinSimple, San Jose, CA, USA).

Statistical analysis. The data are presented as the mean \pm standard deviation from at least three independent experiments. Data was analyzed using SPSS 17 (SPSS, Inc., Chicago, IL, USA). Student's t-test was used to determine statistical significance between two groups. Differences multiple groups were evaluated using one-way analysis of variance followed by a Dunnett multiple-range test. $\mathrm{P}<0.05$ was considered to indicate a statistically significant difference.

\section{Results}

Cinobufacini suppresses proliferation and promotes apoptosis of GC cells. BGC-823 and SGC-7901 cells were 



Figure 1. Biological effects of cinobufacini on gastric cancer cells. Treatment with cinobufacini (A) suppresses the proliferation and (B) promotes the apoptosis of gastric cancer cells. Lower left quadrant, healthy cells; lower right quadrant, early apoptotic cells; upper right quadrant, late apoptotic cells; upper left quadrant, necrotic cells. ${ }^{* *} \mathrm{P}<0.01$ vs. untreated controls. PI, propidium iodide.

treated with different concentrations of cinobufacini $(0,1,5$, 10,50 and $100 \mu \mathrm{g} / \mathrm{ml}$ ) for $24 \mathrm{~h}$ and $48 \mathrm{~h}$. Subsequently, cell viability was measured using a CCK-8 assay kit. The results demonstrated that the growth of GC cells was inhibited by treatment with cinobufacini in a concentration-dependent manner (Fig. 1A). As cinobufacini at the concentrations of 50 and $100 \mu \mathrm{g} / \mathrm{ml}$ exhibited significant toxic effects on the BGC-823 and SGC-7901 cells, the $10 \mu \mathrm{g} / \mathrm{ml}$ concentration of cinobufacini was selected to be used in the subsequent experiments. After treatment with $10 \mu \mathrm{g} / \mathrm{ml}$ cinobufacini for $24 \mathrm{~h}$, the cells were analyzed to detect apoptosis. The results indicated that cinobufacini promoted the apoptosis of BGC-823 cells (control vs. cinobufacini, 5.49 vs. 17.96\%) and SGC-7901 cells (control vs. cinobufacini, 5.93 vs. $22.15 \%$; Fig. 1B).

miR-494 is a tumor suppressor gene and exhibits an opposing expression trend compared with BAG-1 in cinobufacini-treated cells. The expression levels of miR-494 were determined in plasma samples from 50 patients with GC and 50 healthy control subjects. The RT-qPCR analysis indicated that the expression level of miR-494 was lower in patients with GC than in healthy control subjects (Fig. 2A).
The results also suggested that miR-494 may be a tumor suppressor. Thus, we hypothesized that the antitumor activity of cinobufacini may partially be mediated by miR-494. As a previous study demonstrated that BAG-1 is a direct target of miR-494 (16), the expression of miR-494 and BAG-1 was examined in cinobufacini-treated BGC-823 and SGC-7901 cells. The results indicated that expression of miR-494 and BAG-1 exhibited opposing trends of in cinobufacini-treated cells, with miR-494 was upregulated and BAG-1 downregulated by cinobufacini (Fig. 2B and C). The results suggested that miR-494 and BAG-1 are involved in the activity of cinobufacini.

miR-494 reduces the expression of BAG-1 following cinobufacini treatment. To investigate whether miR-494 mediates the decreased expression of BAG-1 and alters cell behaviors in cinobufacini-treated cells, BGC-823 and SGC-7901 cells were treated with cinobufacini for $24 \mathrm{~h}$, and then transfected with a miR-494 inhibitor or a scramble sequence. The transfection efficacy was determined by RT-qPCR (Fig. 3A). The miR-494 inhibitor partially reversed the cinobufacini-induced decreased expression of BAG-1 (Fig. 3B). Additionally, knockdown of miR-494 promoted the growth of GC cells compared 


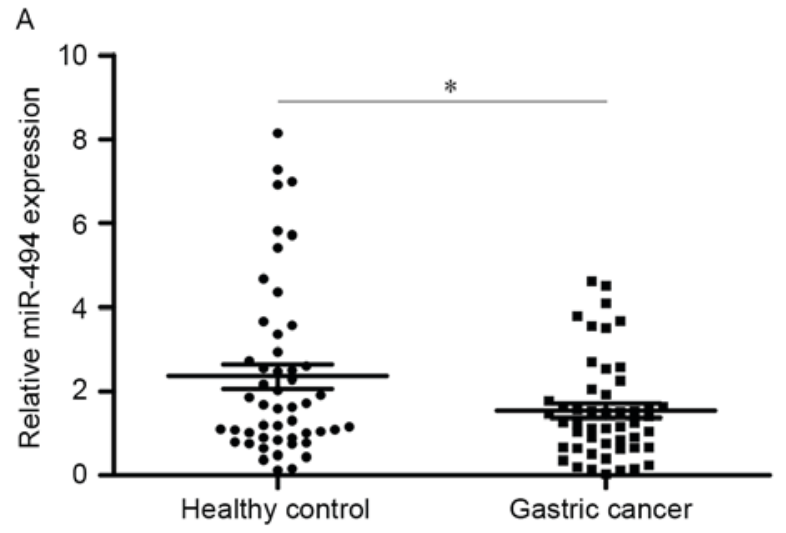

B
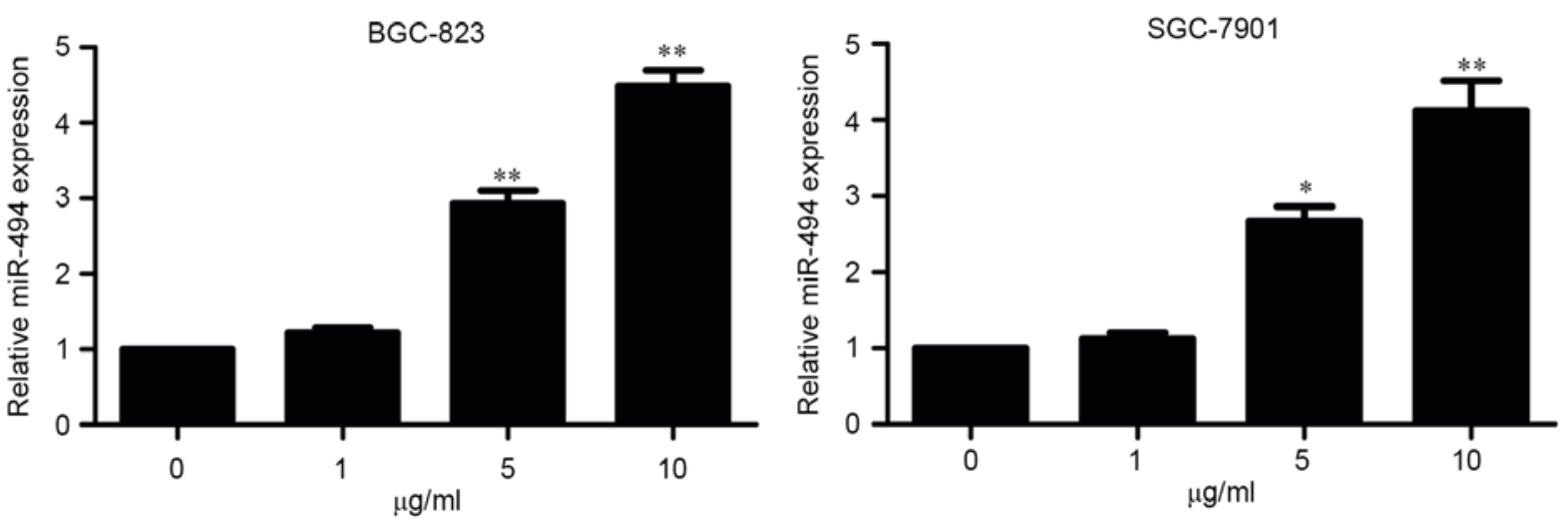

C
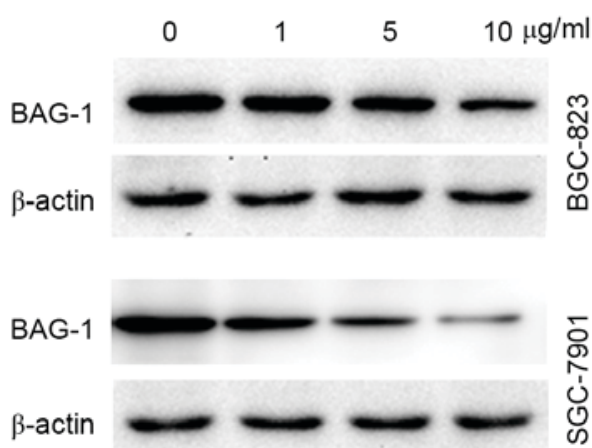

Figure 2. miR-494 and BAG-1 exert opposing expression levels in cinobufacini-treated GC cells. (A) Scatter plots of the fold change of miR-494 in plasma from patients with $\mathrm{GC}$ and healthy controls. "P $<0.05$ vs. healthy control. (B) miR-494 level and (C) BAG-1 protein expression in cinobufacini-treated GC cells. ${ }^{*} \mathrm{P}<0.05,{ }^{* *} \mathrm{P}<0.01$ compared with untreated controls. GC, gastric cancer; miR, microRNA; BAG-1, BCL2 associated athanogene 1.

with the control cinobufacini-treated cells (Fig. 3C). The results of the apoptosis analysis suggested that the miR-494 inhibitor attenuated cinobufacini-induced apoptosis of BGC-823 cells (NC vs. miR-494 inhibitor, 9.69 vs. $4.79 \%$ ) and SGC-7901 cells (NC vs. miR-494 inhibitor, 8.94 vs. $4.36 \%$; Fig. 3D).

Effect of miR-494 on cinobufacini-induced cell proliferation and apoptosis is mediated by BAG-1. To investigate whether the regulatory role of miR-494 on cinobufacini-induced cell behavior changes are dependent on BAG-1 inhibition, the BGC-823 and SGC-7901 cells were treated with cinobufacini for $24 \mathrm{~h}$ and transfected with the miR-494 inhibitor plus BAG-1 siRNA or miR-494 inhibitor plus a scramble sequence (Fig. 4A and B). The data indicated that inhibition of BAG-1 partially abrogated the effects of miR-494 inhibitor on cell proliferation and apoptosis. Knockdown of BAG-1 reduced the growth rates and promoted the apoptotic ability of miR-494-silenced BGC-823 cells (NC vs. BAG-1 siRNA, 5.33 vs. $14.04 \%$ ) and SGC-7901 cells (NC vs. BAG-1 siRNA, 3.75 vs. $7.57 \%$; Fig. 4C and D).

\section{Discussion}

Cinobufacini is a traditional Chinese medicine that has been used for many years. The biological activities of cinobufacini include anesthetic, cardiotonic, antimicrobial and antineoplastic effects (19), thus, it is widely used in the treatment of malignant tumors $(20,21)$. Cinobufacini exhibited great clinical efficacy in the treatment of hepatocellular carcinoma $(22,23)$, non-small-cell lung cancer (24) and advanced gallbladder carcinoma (25). Thus, in the current study the biological 


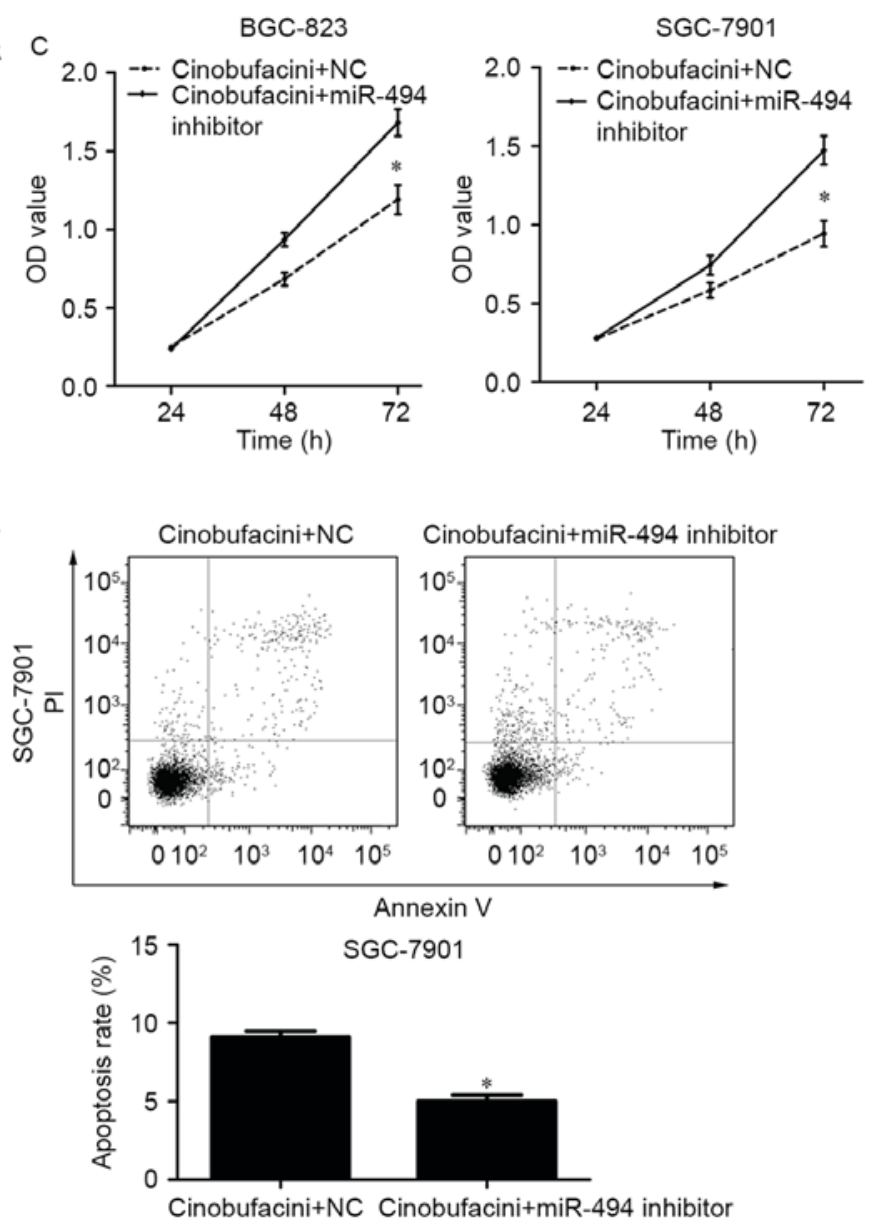

Figure 3. Silencing of miR-494 increases the expression of BAG-1 in cinobufacini-treated GC cells. (A) Expression level of miR-494 is decreased following transfection of the miR-494 inhibitor. (B) Protein level of BAG-1 is upregulated in cinobufacini-treated cells following inhibition of miR-494. (C) Knockdown of miR-494 promotes cell proliferation and (D) inhibits cell apoptosis in cinobufacini-treated cells. "P<0.05 vs. cinobufacini $+\mathrm{NC}$. NC, negative control; miR, microRNA; BAG-1, BCL2 associated athanogene 1; PI, propidium iodide.

function and underlying mechanisms of cinobufacini were investigated in GC cells.

In the present study, the anti-proliferative and pro-apoptotic activities of cinobufacini were evaluated in GC cells, and the results were consistent with previous studies $(26,27)$. Our previous microarray study on cinobufacini-treated BGC-823 cells demonstrated that miR-494 was upregulated by cinobufacini (16). Furthermore, miR-494 was reported to be involved in regulation of the tumorigenesis of various cancer types $(14,15,28)$. Accordingly, the expression profile of miR-494 was evaluated in the plasma of patients with GC and healthy control subjects. The result indicated miR-494 was downregulated in blood samples from patients with GC, which was in accordance with previous studies on GC tissues $(11,14,29)$. We previously reported that miR-494 inhibited BGC-823 cell proliferation and promoted apoptosis, thus, we hypothesize that cinobufacini-induced cancer cell apoptosis may be partially mediated by miR-494.

miRNAs exert their functional effects by regulating target genes, and the results of the current study demonstrated that BAG-1 is a direct target of miR-494 (16), thus the expression of BAG-1 was analyzed in cinobufacini-treated GC cells. The results demonstrated that BAG-1 exhibited an opposing expression level trend compared with miR-494, and was decreased by cinobufacini in a concentration-dependent manner, suggesting miR-494 and BAG-1 are involved in the antitumor activity of cinobufacini.

BAG-1 is a multifunctional protein that is over-expressed in various cancer types and regulated in a wide variety of cellular processes, including proliferation, apoptosis, metastasis and cell survival (30-33). The most important function of BAG-1 is the enhancement of the anti-apoptotic ability of Bcl-2; thus, we hypothesized that miR-494 may regulate cinobufacini-induced cell proliferation and apoptosis by targeting BAG-1. Notably, following silencing of miR-494 in cinobufacini-treated GC cells, the expression of BAG-1 was decreased, and the inhibitory effects of cinobufacini on cell proliferation and apoptosis were attenuated. Knockdown BAG-1 in the miR-494-silenced and cinobufacini-treated GC cells reduced cell viability and enhanced apoptosis. Our previous study demonstrated that miR-494 may participate in the anti-tumor activity of cinobufacini (16). In the present study, the data demonstrated that cinobufacini inhibited cell proliferation and promoted apoptosis via the upregulation of miR-494 and subsequent downregulation of its target, BAG-1. The present study focused on the role of miR-494 and BAG-1 in cinobufacini-induced proliferation and apoptosis of GC 

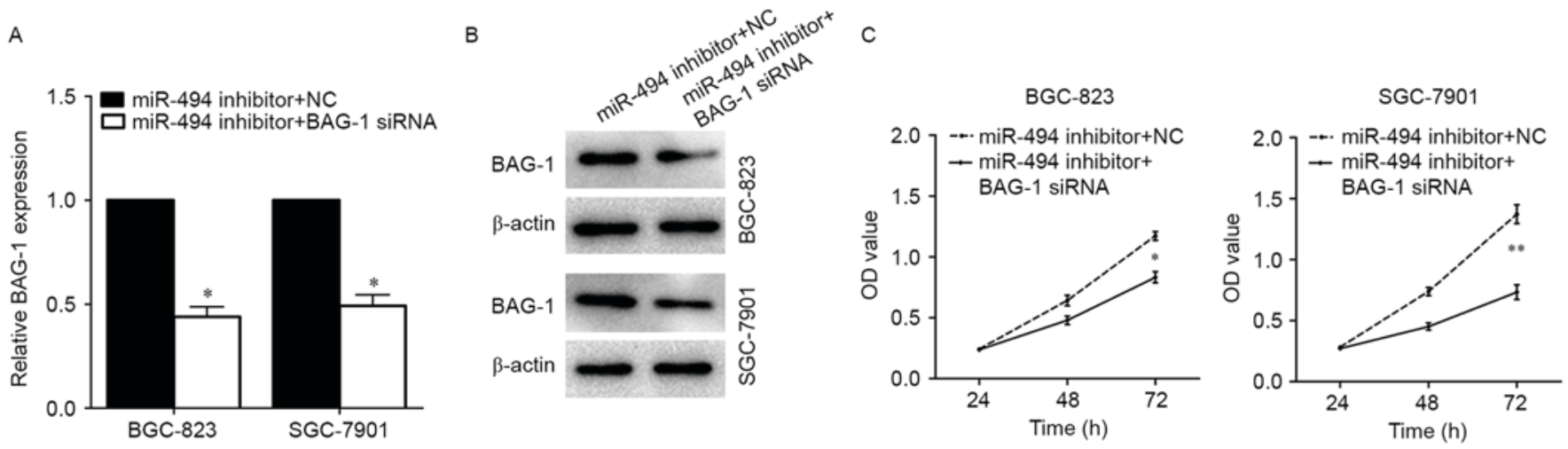

D
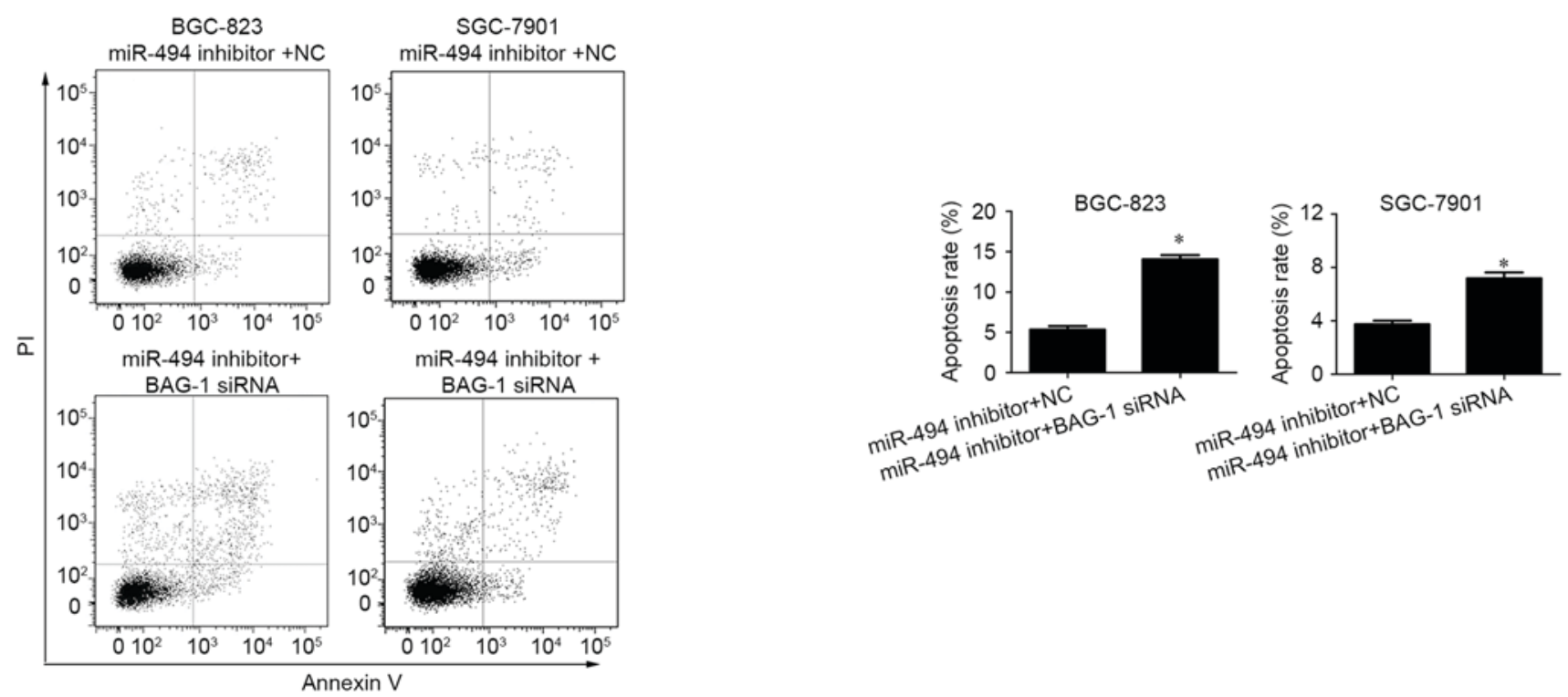

Figure 4. Knockdown of BAG-1 partially abrogates the effects of miR-494 inhibitor on cell proliferation and apoptosis in cinobufacini-treated GC cells. Expression levels of (A) miR-494 and (B) BAG-1 protein following transfection of miR-494 inhibitor and BAG-1 siRNA in cinobufacini-treated gastric cancer cells. (C) Proliferation of cinobufacini-treated cells was inhibited and (D) apoptosis was enhanced following double-silencing of miR-494 and BAG-1. ${ }^{*} \mathrm{P}<0.05,{ }^{* *} \mathrm{P}<0.01$ vs. miR inhibitor + NC. miR, microRNA; BAG-1, BCL2 associated athanogene 1; siRNA, small interfering RNA; NC, negative control; PI, propidium iodide.

cells; however, cinobufacini exhibits a variety of clinical effects. Thus, future studies are required to investigate the underlying molecular mechanism of cinobufacini in the treatment of GC.

In conclusion, the results of the present study demonstrated that cinobufacini suppresses GC cells proliferation and promotes apoptosis, partially via the miR-494-BAG-1 axis. These findings provide a new insight into the mechanism of the effects of cinobufacini in GC. Futures studies should investigate the molecular mechanisms underlying the effect of miR-494-BAG-1 axis resulting in the suppression of GC cell proliferation and promote apoptosis.

\section{Acknowledgments}

Not applicable.

\section{Funding}

This study was supported by the Science and Technology Development Plan of the Jiangning District (grant no. 2015Eg06) and the Nanjing Health Bureau Research Project (grant no. YKK14194).

\section{Availability of data and materials}

The datasets used and/or analyzed during the current study are available from the corresponding author on reasonable request.

\section{Authors' contributions}

RPZ and ZLS conceived and designed the experiments. GC and YL collected the blood samples and evaluated the data from the patients. CCZ and FW performed the experiments. ZLS and GC wrote the manuscript. All authors read and approved the final manuscript.

\section{Ethics approval and consent to participate}

This study was approved by the Ethical Committee of Jiangning Hospital (Nanjing, China). Written informed consent was obtained from all of the participants. 


\section{Consent for publication}

Consent forms for the publication of associated data were obtained from all participants.

\section{Competing interests}

The authors declare that they have no competing interests.

\section{References}

1. Torre LA, Bray F, Siegel RL, Ferlay J, Lortet-Tieulent J and Jemal A: Global cancer statistics, 2012. CA: CA Cancer J Clin 65: 87-108, 2015.

2. Chen W, Zheng R, Baade PD, Zhang S, Zeng H, Bray F, Jemal A, $\mathrm{Yu}$ XQ and He J: Cancer statistics in China, 2015. CA Cancer J Clin 66: 115-132, 2016.

3. Qi F, Li A, Zhao L, Xu H, Inagaki Y, Wang D, Cui X, Gao B, Kokudo N, Nakata M, et al: Cinobufacini, an aqueous extract from Bufo bufo gargarizans Cantor, induces apoptosis through a mitochondria-mediated pathway in human hepatocellular carcinoma cells. J Ethnopharmacol 128: 654-661, 2010.

4. Wang D and Bi Z: Bufalin inhibited the growth of human osteosarcoma MG-63 cells via down-regulation of Bcl-2/Bax and triggering of the mitochondrial pathway. Tumour Biol 35 : 4885-4890, 2014.

5. Qi F, Li A, Inagaki Y, Xu H, Wang D, Cui X, Zhang L, Kokudo N, Du G and Tang W: Induction of apoptosis by cinobufacini preparation through mitochondria- and Fas-mediated caspase-dependent pathways in human hepatocellular carcinoma cells. Food Chem Toxicol 50: 295-302, 2012.

6. Ma L, Song B, Jin H, Pi J, Liu L, Jiang J and Cai J: Cinobufacini induced MDA-MB-231 cell apoptosis-associated cell cycle arrest and cytoskeleton function. Bioorg Med Chem Lett 22: 1459-1463, 2012.

7. Lee S, Lee Y, Choi YJ, Han KS and Chung HW: Cyto-/genotoxic effects of the ethanol extract of Chan Su, a traditional Chinese medicine, in human cancer cell lines. J Ethnopharmacol 152: 372-376, 2014.

8. Xie X, Huang X, Li J, Lv X, Huang J, Tang S and Sun Y: Efficacy and safety of Huachansu combined with chemotherapy in advanced gastric cancer: A meta-analysis. Med Hypotheses 81: 243-250, 2013

9. Yang J, Zhu L, Wu Z and Wang Y: Chinese herbal medicines for induction of remission in advanced or late gastric cancer. Cochrane Database Syst Rev (Issue 4): CD005096, 2013.

10. Bartel DP: MicroRNAs: Genomics, biogenesis, mechanism, and function. Cell 116: 281-297, 2004

11. He W, Li Y, Chen X, Lu L, Tang B, Wang Z, Pan Y, Cai S, He Y and Ke Z: MiR-494 acts as an anti-oncogene in gastric carcinoma by targeting c-myc. J Gastroenterol Hepatol 29: 1427-1434, 2014.

12. Nip H, Dar AA, Saini S, Colden M, Varahram S, Chowdhary H, Yamamura S, Mitsui Y, Tanaka Y, Kato T, et al: Oncogenic microRNA-4534 regulates PTEN pathway in prostate cancer. Oncotarget 7: 68371-68384, 2016.

13. Song L, Liu D, Wang B, He J, Zhang S, Dai Z, Ma X and Wang X: MiR-494 suppresses the progression of breast cancer in vitro by targeting CXCR4 through the Wnt/beta-catenin signaling pathway. Oncol Rep 34: 525-531, 2015.

14. Li N, Zhao X, Wang L, Zhang S, Cui M and He J: MiR-494 suppresses tumor growth of epithelial ovarian carcinoma by targeting IGF1R. Tumour Biol 37: 7767-7776, 2016.

15. Chen B, Hou Z, Li C and Tong Y: MiRNA-494 inhibits metastasis of cervical cancer through Pttg1. Tumour Biol 36: 7143-7149, 2015.

16. Zhou RP, Chen G, Shen ZL and Pan LQ: Cinobufacin suppresses cell proliferation via miR-494 in BGC-823 gastric cancer cells. Asian Pac J Cancer Prev 15: 1241-1245, 2014.

17. Clemo NK, Collard TJ, Southern SL, Edwards KD, Moorghen M, Packham G, Hague A, Paraskeva C and Williams AC: BAG-1 is up-regulated in colorectal tumour progression and promotes colorectal tumour cell survival through increased NF-kappaB activity. Carcinogenesis 29: 849-857, 2008.
18. Livak KJ and Schmittgen TD: Analysis of relative gene expression data using real-time quantitative PCR and the 2(-Delta Delta C(T)) method. Methods 25: 402-408, 2001.

19. Qi F, Inagaki Y, Gao B, Cui X, Xu H, Kokudo N, Li A and Tang W: Bufalin and cinobufagin induce apoptosis of human hepatocellular carcinoma cells via Fas- and mitochondria-mediated pathways. Cancer Sci 102: 951-958, 2011.

20. Zhai XF, Chen Z, Li B, Shen F, Fan J, Zhou WP, Yang YK, Xu J, Qin X, Li LQ, et al: Traditional herbal medicine in preventing recurrence after resection of small hepatocellular carcinoma: A multicenter randomized controlled trial. J Integr Med 11: 90-100, 2013.

21. Meng Z, Garrett CR, Shen Y, Liu L, Yang P, Huo Y, Zhao Q, Spelman AR, Ng CS, Chang DZ, et al: Prospective randomised evaluation of traditional Chinese medicine combined with chemotherapy: A randomised phase II study of wild toad extract plus gemcitabine in patients with advanced pancreatic adenocarcinomas. Br J Cancer 107: 411-416, 2012.

22. Dong J, Zhai X, Chen Z, Liu Q, Ye H, Chen W and Ling C: Treatment of huge hepatocellular carcinoma using Cinobufacini injection in transarterial chemoembolization: A retrospective study. Evid Based Complement Alternat Med: 2754542, 2016.

23. Chen Z, Chen HY, Lang QB, Li B, Zhai XF, Guo YY, Yue XQ and Ling CQ: Preventive effects of jiedu granules combined with cinobufacini injection versus transcatheter arterial chemoembolization in post-surgical patients with hepatocellular carcinoma: A case-control trial. Chin J Integr Med 18: 339-344, 2012.

24. Jiang Y, Liu LS, Shen LP, Han ZF, Jian H, Liu JX, Xu L, Li HG, Tian JH and Mao ZJ: Traditional Chinese Medicine treatment as maintenance therapy in advanced non-small-cell lung cancer: A randomized controlled trial. Complement Ther Med 24: 55-62, 2016.

25. Qin TJ, Zhao XH, Yun J, Zhang LX, Ruan ZP and Pan BR: Efficacy and safety of gemcitabine-oxaliplatin combined with huachansu in patients with advanced gallbladder carcinoma. World J Gastroenterol 14: 5210-5216, 2008.

26. Wu Q, Lin WD, Liao GQ, Zhang LG, Wen SQ and Lin JY: Antiproliferative effects of cinobufacini on human hepatocellular carcinoma HepG2 cells detected by atomic force microscopy. World J Gastroenterol 21: 854-861, 2015.

27. Yin JQ, Wen L, Wu LC, Gao ZH, Huang G, Wang J, Zou CY, Tan PX, Yong BC, Jia Q, et al: The glycogen synthase kinase-3beta/nuclear factor-kappa B pathway is involved in cinobufagin-induced apoptosis in cultured osteosarcoma cells. Toxicol Lett 218: 129-136, 2013.

28. Li J, Wang L, Liu Z, Zu C, Xing F, Yang P, Yang Y, Dang X and Wang K: MicroRNA-494 inhibits cell proliferation and invasion of chondrosarcoma cells in vivo and in vitro by directly targeting SOX9. Oncotarget 6: 26216-26229, 2015.

29. Shrestha S, Hsu SD, Huang WY, Huang HY, Chen W, Weng SL and Huang HD: A systematic review of microRNA expression profiling studies in human gastric cancer. Cancer Med 3: 878-888, 2014

30. Ni W, Chen B, Zhou G, Lu C, Xiao M, Guan C, Zhang Y, He S, Shen A and Ni R: Overexpressed nuclear BAG-1 in human hepatocellular carcinoma is associated with poor prognosis and resistance to doxorubicin. J Cell Biochem 114: 2120-2130, 2013.

31. Sun NF, Meng QY, Hu SY, Tian AL, Wang RH, Liu ZX and $\mathrm{Xu}$ L: Correlation between the expression of the BAG-1 gene and clinicopathologic factors in colorectal cancer. J Cancer Res Clin Oncol 137: 1419-1424, 2011.

32. Zheng HC, Xu XY, Xing YN, Wei ZL, Takahashi H, Masuda S and Takano Y: Nuclear or cytoplasmic localization of Bag-1 distinctly correlates with pathologic behavior and outcome of gastric carcinomas. Hum Pathol 41: 724-736, 2010.

33. Krajewska M, Turner BC, Shabaik A, Krajewski S and Reed JC: Expression of BAG-1 protein correlates with aggressive behavior of prostate cancers. Prostate 66: 801-810, 2006. 